
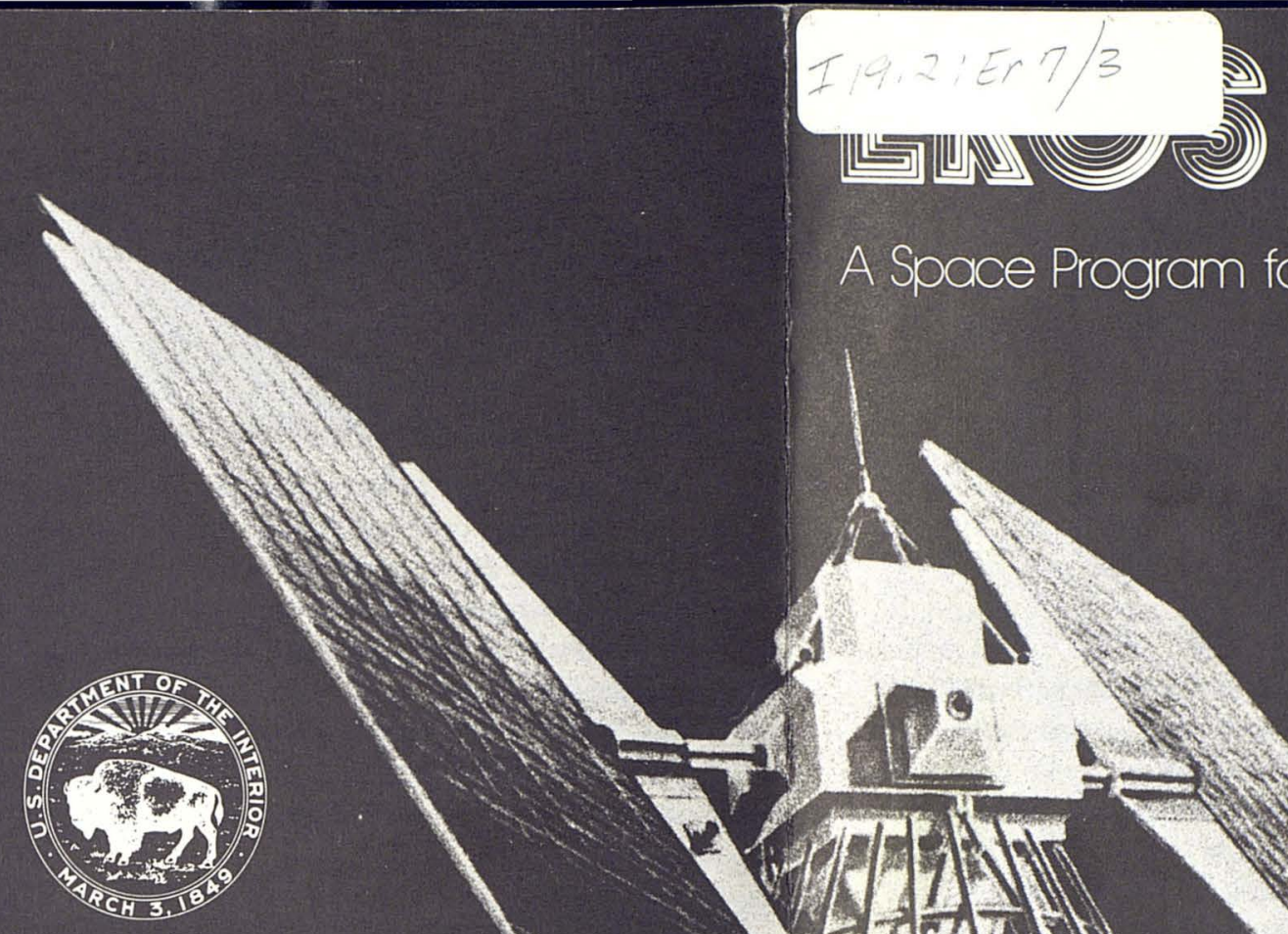

As the Nation's principal conservation agency, the Department of the Interior has responsibility for most of our nationally owned public lands and natural resources. This includes fostering the wisest use of our land and water resources, protecting our fish and wildlife, preserving the environmental and cultural values of our national parks and historical places, and providing for the enjoyment of life through outdoor recreation. The Department assesses our energy and mineral resources and works to assure that their development is in the best interests of all our people. The Department also has a major responsibility for American Indian reservation communities and for people who live in Island Territories under U.S. administration.

\title{
A Space Program for Earth Resources
}




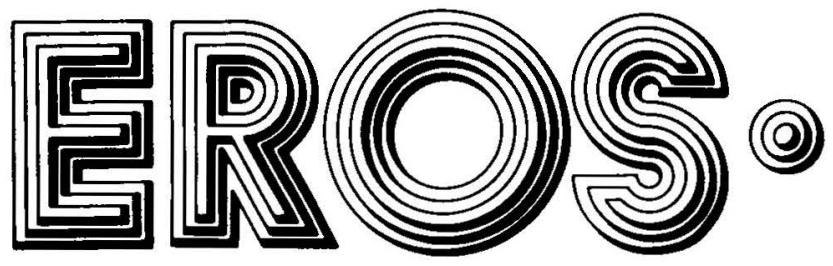

Within the technology of the space age lies a key to increased knowledge about the resources and environment of the Earth. This key is remote sensing-detecting the nature of an object without actually touching it. Although the photographic camera is the most familiar remote-sensing device, there are also other instrument systems, such as scanning radiometers and radar, that can produce photographs and images.

On the basis of the potential of this technology, and in response to the critical need for greater knowledge of the Earth and its resources, the Department of the Interior established the Earth Resources Observation Systems (EROS) Program to gather and use remotely sensed data collected by satellite and aircraft of natural and manmade features on the Earth's surface.

The EROS Program, administered by the U. S. Geological Survey, works with representatives of departmental bureaus and offices to coordinate research and application of remote-sensing technology to the dayto-day operations of the department. Most of the research and applications have been made possible by the experimental data acquisition systems of the National Aeronautics and Space Administration (NASA). In particular, the EROS Program uses data from the Earth Resources Technology Satellite (ERTS), from the Earth Resources Experiment Package (EREP) of Skylab, and from NASA's Aircraft Program.

The potential application of remote-sensing techniques for inventorying and managing the Nation's Earth resources and monitoring our environment has been demonstrated in many ways. ERTS imagery, because of its synoptic coverage, has, for example, identified previously unmapped geologic structures as targets for exploration for oil, gas, copper, and other minerals, and 


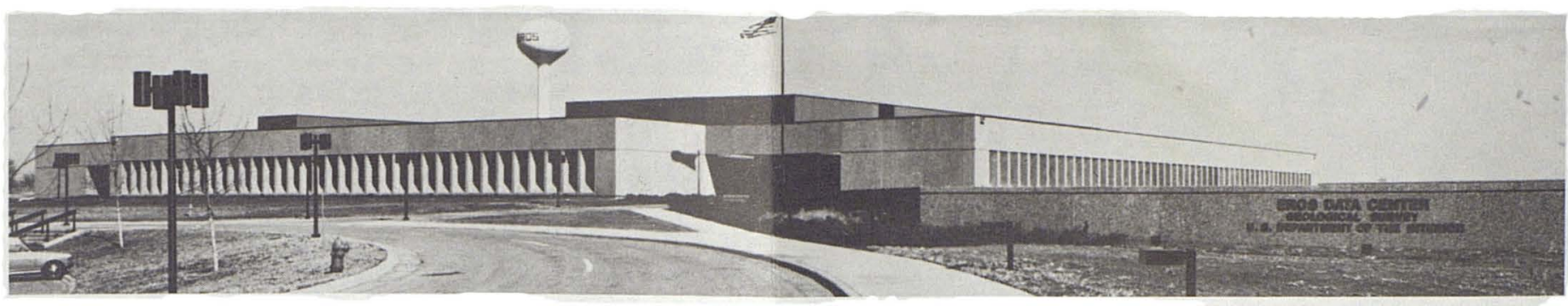

is being used to inventory water impoundment areas. The repetitive coverage of satellite data provides information for land-use planning with a timeliness not previously possible. The capability of detecting changes in land use has proved effective in monitoring strip mining and reclamation of strip mines and will be useful for gaging the environmental impact of the construction of the Alaskan pipeline. It is also used for evaluating range conditions over vast areas of the site about $25 \mathrm{~km}$ (16 miles) northeast of Sioux Falls, South Dakota, serves these functions. The Data Center reproduces and distributes as sale items copies of imagery, photography, electronic data, and computer products collected by 16 different organizations, including the U.S. Geological Survey and NASA.

Training courses are offered at the EROS Data Center to develop government and public capabilities to manipulate, interpret, and use remotely sensed data. The courses range from 1 to 4 weeks and may be oriented to specific disciplines or to the basic understanding of remotely sensed data and its various applications.

The EROS Program Library, dedicated to all aspects of remote sensing, is located at the Data Center. The collection of more than 7,000 titles consists of books, monographs, periodicals, reprints, and reports in paper

\section{A Space Program for Earth Resources}

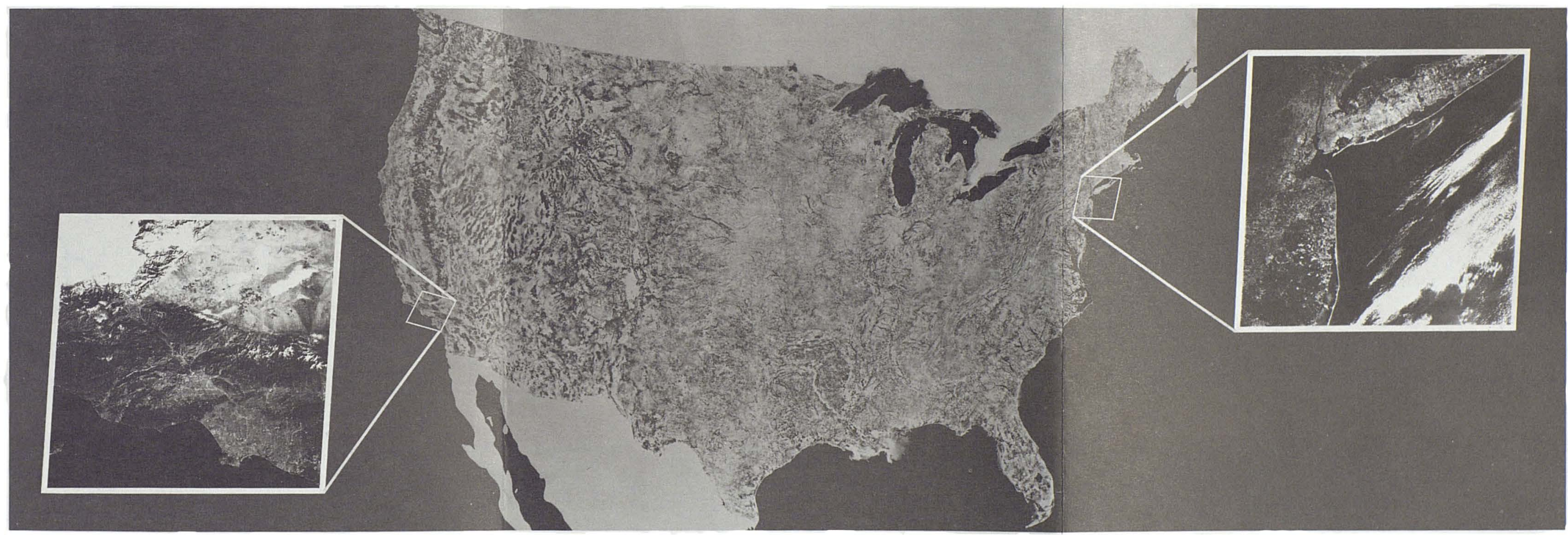

Mosaic prepared by U.S. Soil Conservation Service from 595 satellite images obtained by NASA's Earth Resources Technology Satellite (ERTS). On the left is an insert of a single ERTS image of the Los Angeles, California area and on the right one of the New York/New Jersey area. These images are similar to those used in U.S. mosaic. 


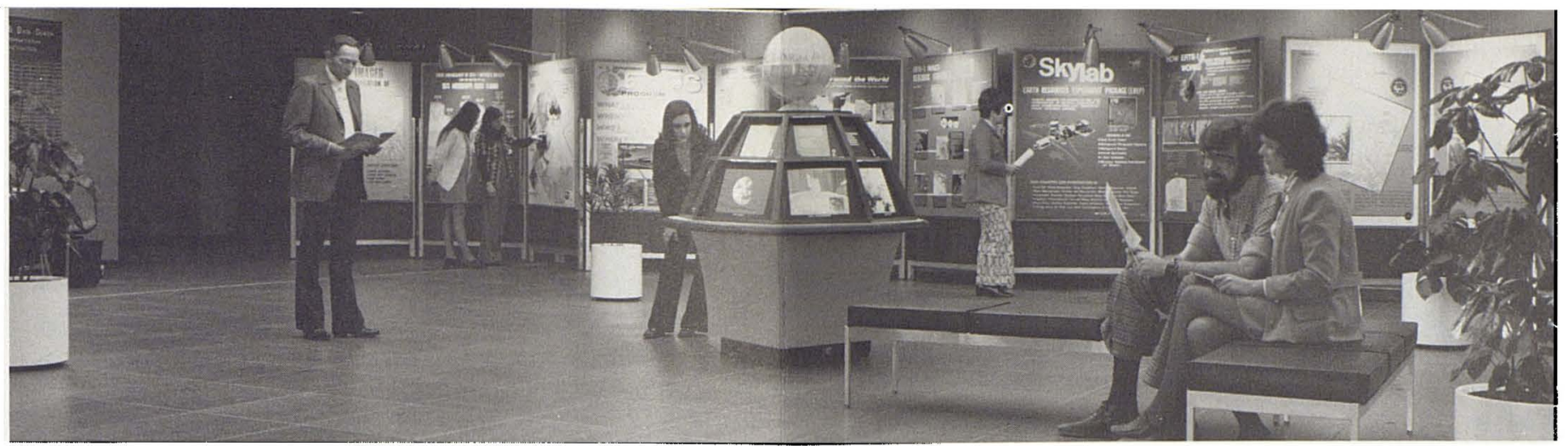

Visitors to the Data Center examine displays explaining the functions of the EROS Program.

copy or on microfiche. The library, a research tool for students in training at the Center as well as for visitors, is an archives for the EROS Program and services interlibrary loans.

The national scope of EROS Program activities has led to the creation of more than 20 local centers where one or more of the following services are available: Browse films of ERTS and Skylab imagery available from the Data Center can be viewed and assistance in ordering data will be provided, equipment for remotesensor data manipulation is available for use, and reference collections of the EROS Program Library are maintained. The most comprehensive services, including training geared to local area needs, are available at the
EROS Applications Assistance Facilities at the National Space Technology Laboratories, Bay St. Louis, Mississippi 39520 and the U.S. Geological Survey, 345 Middlefield Road, Menlo Park, California 94025.

Additional information about the EROS Program can be obtained by writing to EROS Program, U. S. Geological Survey, 1925 Newton Square East, Reston, Virginia 22090. Descriptions of products available from the EROS Data Center, order forms, and price lists can be obtained from the EROS Data Center, Sioux Falls, South Dakota 57198, Tel. 605/594-6511. The Data Center will also provide information about training on request.

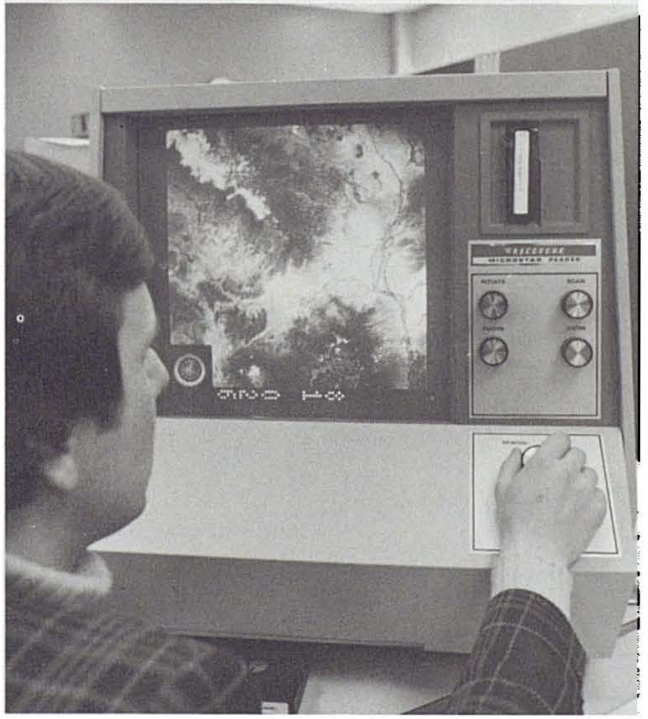

Viewing microfilm of Skylab imagery, EROS Data Center, Sioux Falls, South Dakota.

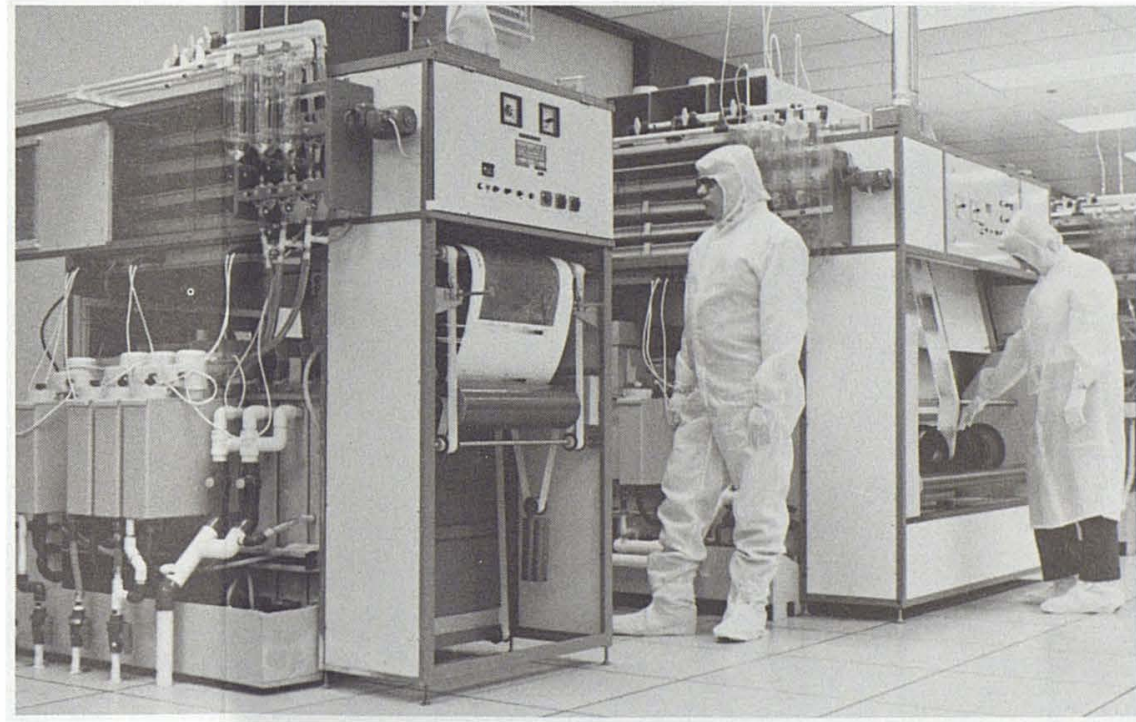

Personnel of a production photo laboratory are clad in protective clothing to maintain the ultra-clean laboratory environment. 